\title{
Reproductive health knowledge, attitudes and practices of adolescents attending an obstetric unit in Georgetown, Guyana
}

\author{
Elizabeth M Rose, ${ }^{1}$ Daghni Rajasingam, ${ }^{2}$ Ruth C Derkenne, ${ }^{3}$ \\ Vivienne Mitchell, ${ }^{4}$ Anita A Ramlall ${ }^{5}$
}

\begin{abstract}
${ }^{1}$ FY2, Chalmers Sexual Health Centre, Edinburgh, UK ${ }^{2}$ Consultant Obstetrician, Department of Obstetrics and Gynaecology, KHP Women's Health Academic Centre, St Thomas' Hospital, London, UK ${ }^{3}$ Consultant Obstetrician, Obstetrics/Gynaecology Residency Program, Georgetown Public Hospital Corporation, Georgetown, Guyana

${ }^{4}$ Consultant Anaesthetist, Department of Anaesthetics, Georgetown Public Hospital Corporation, Georgetown, Guyana

${ }^{5}$ Senior resident, Obstetrics and Gynaecology, Obstetrics/ Gynaecology Residency Program, Georgetown Public Hospital Corporation, Georgetown, Guyana
\end{abstract}

\section{Correspondence to} Dr Elizabeth M Rose, Chalmers Sexual Health Centre, Chalmers Street, Edinburgh EH3 9HQ, UK elizabethrose1@nhs.net

Received 2 June 2014 Revised 30 July 2015 Accepted 3 September 2015 Published Online First 24 September 2015

\section{CrossMark}

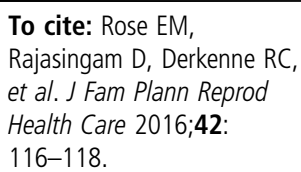

\begin{abstract}
Background Teenage pregnancy continues to be a serious maternal health issue globally. Problems faced by teenage mothers are biological, social, and psychological, and may include sexual coercion and violence. This study sought to explore formally the knowledge, attitudes and practices of pregnant teenagers in Georgetown, Guyana, which has one of the highest rates of teenage pregnancy in Latin America and the Caribbean.
\end{abstract}

Methods This was a cross-sectional, prospective study. After ethical approval had been granted, 50 pregnant girls attending Georgetown Public Hospital Corporation (GPHC) were interviewed during a 6-week period. Using a convenience sample approach, the principal investigator used a questionnaire to collect data. This was then analysed using Stata/SE V.9.2 and Microsoft Excel programs.

Findings As well as overall poor sexual and reproductive health knowledge and high-risk sexual health practices, our study revealed a high rate of rape and sexual coercion among the 50 girls interviewed. Almost a quarter (22\%) admitted to having been raped in the past, and $80 \%$ stated a lack of power in their sexual relationships.

Conclusions There is a need for more targeted sexual and reproductive health services for teenagers attending GPHC, and for more research into sexual violence among this group of women. The establishment of a screening and referral system for those at risk should begin to address specific issues and optimise health outcomes for the women and their babies.

\section{INTRODUCTION}

Teenage pregnancy continues to be a serious maternal health issue globally. ${ }^{1}$

\section{Key message points}

- Many teenagers attending Georgetown Public Hospital Corporation obstetric unit in Guyana are inadequately informed about sexual and reproductive health, and a high rate of rape and sexual coercion was incidentally discovered.

- The establishment of a teenage pregnancy clinic should begin to address specific problems at the unit and target those most at risk of sexual violence.

- More research is needed to uncover the true extent of these problems both locally and globally.

Problems faced by teenage mothers are biological, social, and psychological, and may include sexual coercion and violence. ${ }^{2}$ The aim of this study was to explore formally the knowledge, attitudes, perceptions and behaviours of pregnant teenagers attending Georgetown Public Hospital Corporation (GPHC), Guyana, which has one of the highest rates of teenage pregnancy in Latin America and the Caribbean. ${ }^{3}$ The objective was to develop a better understanding of the needs of these teenagers, and to identify any gaps in services. In this way it was hoped to explore the possibility of targeted interventions for this population, which would take advantage of the increased contact these young women have with healthcare professionals during the antenatal period. The results and discussion in this report focus on the incidental findings of rape and sexual coercion among the cohort and form part of a larger study. 


\section{METHODS}

\section{Design setting}

Guyana is the only English-speaking country in South America. It lies on the north-east of the continent, flanked by Venezuela to the west, Brazil to the south, Suriname to the east, and the Atlantic Ocean to the north. GPHC is the national tertiary referral hospital and provides inpatient, outpatient, antenatal and postnatal care to women. Situated in the capital city, all women with high-risk pregnancies are referred there.

The legal age for marriage in Guyana is 16 years with parental or high court permission, and 18 years without. ${ }^{4}$ If a girl aged under 16 years is pregnant or has a child, permission may be granted for her to marry the father of the child regardless of his age. The age of consent to any kind of sexual activity is 16 years ${ }^{5}$ for both sexes.

The most recent available data in Guyana reveal a total of 3310 child abuse cases involving children aged under 16 over the 1 year period JanuaryDecember 2013, of which $20 \%$ were sexual in nature. ${ }^{6}$ The majority $(88 \%)$ of this sexual abuse was perpetrated against girls. The same source reveals 51 cases of incest over a 6-month period in 2012. In 50 of these cases the victim was a girl, and four pregnancies were documented.

\section{Participants}

Inclusion criteria:

subjects aged 10 to $<20$ years attending GPHC antenatal clinic and on pre- and postnatal wards; and able to speak English.

Exclusion criteria:

subjects aged $\geq 20$ years; requiring emergency care; and unable to communicate in English.

\section{Interventions}

Over a 6 week period from 6 August to 14 September 2012, the principal investigator attended the wards at GPHC twice daily from Monday to Friday, and all pregnant teenagers attending GPHC during these times who fulfilled the above criteria were approached to participate in the study. This gave a total of 73 eligible participants, of whom 51 agreed to participate; however, one was unable to complete the interview adequately due to poor English, leaving a total of 50 girls included in the study. This number represents $27 \%$ of the total of 186 pregnant teenagers who were seen in clinic or admitted to the unit over this time. A structured questionnaire adapted from a framework approved by the World Health Organization ${ }^{7}$ was used to gather quantitative and qualitative data on sexual and reproductive health issues.

\section{Analysis}

Statistical evaluation was carried out by the principal investigator using Stata/SE V.9.2 (StataCorp, Texas, USA) and Microsoft Excel programs.

\section{RESULTS}

A total of 50 girls aged 11-19 years (average age 17 years) were included in the study. Forty-three girls $(86 \%)$ were single (never married), with 11 (22\%) being in no relationship at the time of interview. The majority (70\%) of the pregnancies were unplanned.

The average age of first intercourse among the group was 15 years, while the youngest was 10 years. Overall, the average difference in age between the girls and the child's father was 6 years (with the man being the same age or older in every case). The largest age gap was 32 years. Thirty-five $(70 \%)$ of the girls had boyfriends at least 4 years older at the time of interview: of these, 11 of the girls were aged under 16 . Ten girls $(20 \%)$ had partners who were 8 or more years older. Of these, seven (70\%) were under 18 the first time they had sex with their partners, and three $(30 \%)$ said they had not wanted to have sex at the time. Two of these girls had been raped.

Among the married cohort this age difference was smaller at 3.85 years, with the biggest age difference in this group being 8 years. Following on from this, of the seven girls in the group who were married, the average age at marriage was 17 years. Two girls married at age 16, three at age 17, and two at age 18 . For five of these girls (71\%), their first experience of sexual intercourse was with the father of their current pregnancy compared to $25(58 \%)$ of the unmarried cohort, or $30(60 \%)$ overall.

Only 10 girls $(20 \%)$ said they had the power to decide when and when not to use contraception, despite the majority (84\%) believing it was the woman's responsibility to ensure its proper use. Fifty per cent said they worried about getting pregnant, and $52 \%$ were concerned about sexually transmitted infections. In $42 \%$ of cases no form of protection was used the first time they had sex with their child's father, and fewer than $10 \%$ used protection at every encounter.

Overall, $32(64 \%)$ of the girls said they regretted the first time they had had sex (this was only marginally less among the married group at 57\%); 15 (30\%) said the first time they had sex with their child's father they did not want to; and 11 (22\%) disclosed that they had been raped at some point in the past. Of the latter, five were assaulted by family members or friends. In one case the perpetrator was the child's father. She went on to give birth via a planned caesarean section delivery aged 11 years.

\section{DISCUSSION}

We found a high incidence of rape and/or sexual coercion among those subjects interviewed, with almost a quarter admitting to having been raped at some point. Child marriage (defined as marriage below the age of $18^{8}$ ) was also evident, affecting five of the girls interviewed (10\% of total). In general, attitudes surrounding sex and relationships suggest gender based 
inequalities with regard to responsibility and power within relationships, which undermine the fundamental sexual and reproductive rights of these girls. The majority felt that the onus for contraceptive use was on them; however, very few admitted that in practice they had the power to decide whether or not to use it. In these cases the consequences of an unintended pregnancy may unfortunately perpetuate a cycle of inequality and discrimination for some of these young women.

Since the presentation of these results at a local conference in 2012, several interventions have been instituted. There is now universal intimate partner violence/sexual assault and sexually transmitted infection screening in the antenatal clinic. In addition, a teenage pregnancy clinic has been established which provides antenatal and postnatal care to women under the age of 20; antenatal classes which cover family planning, sexual health, women's health, newborn care and early parenting skills, as well as promoting return to school and vocational training; a validated 10-week cognitive behavioural intervention programme for girls who have experienced, or are at high risk of, sexual assault or other trauma; and a dedicated advocate for teenage girls, accessible to them in outpatient clinics and throughout their antenatal, delivery and postpartum admissions.

\section{CONCLUSIONS}

This was a small observational study and may not be representative of the broader country picture, for which more research is required. However, the information gathered offers a useful insight into the needs of pregnant adolescents at GPHC. If successful, it is hoped that the interventions that followed should begin to address some of the problems highlighted. By intervening at this stage we hope to improve understanding and awareness of reproductive health issues including sexual coercion and violence. Consequently, the outlook may be brighter for these women and their babies.
Acknowledgements Thanks to Dr Venkatraman Chandra-Mouli and Dr John Rose for their helpful advice and comments.

Funding We would like to thank the Royal College of Obstetricians and Gynaecologists, Ethicon, Wellbeing of Women, Medical Women's Federation and The Vandervell Foundation for generously funding this study. No payment has been received from a pharmaceutical company or any other agency.

Competing interests The Royal College of Obstetricians and Gynaecologists, Ethicon, Wellbeing of Women, Medical Women's Federation and The Vandervell Foundation did not have any role in study design, data collection and analysis, write-up, or any aspect pertinent to this study, including the decision to submit the paper for publication.

Patient consent Obtained.

Ethics approval The study was approved by the Guyana Ministry of Health.

Provenance and peer review Not commissioned; externally peer reviewed.

Data sharing statement All authors had access to the complete data file, and made the decision to submit for publication. Any remaining published data are stored on a password locked computer to which only the corresponding author has access.

\section{REFERENCES}

1 Bearinger LH, Sieving RE, Ferguson BJ, et al. Global perspectives on the sexual and reproductive health of adolescents: patterns, prevention, and potential. Lancet 2007;369:1220-1231.

2 World Health Organization. Adolescent Friendly Health Services: An Agenda for Change. Geneva: WHO, 2002.

3 United Nations FPA. State of the World Population 2013: Motherhood in Childhood-Facing the Challenge of Adolescent Pregnancy. UNFPA, 2013.

4 Laws of Guyana. Chapter 45:01. Marriage Act. 1998. http:// jafbase.fr/DocAmeriques/Guyana/LoiMariage.pdf [last accessed 30 July 2010].

5 Guyana Sexual Offenses Act No. 7. 2010. http://scm.oas.org/ pdfs/2010/CIM02920T-2.pdf [last accessed 30 July 2015].

6 Guyana Ministry of Labour, Human Services and Social Security. http://www.mlhsss.gov.gy [last accessed 30 July 2015].

7 Cleland J. Illustrative questionnaire for interview-surveys with young people. In: Cleland J, Ingham R, Stone N, eds. Asking Young People About Sexual and Reproductive Behaviors. Illustrative Core Instruments. Geneva: WHO, 2001.

8 World Health Organization. Early Marriages, Adolescent and Young Pregnancies. Report by the Secretariat. Geneva: WHO, 2012. 